\title{
Image Technologies in the Development of Female Management Style Features
}

\author{
Anar Valieva \\ PhD Doctoral, Senior Teacher; Kazakhstan University for Economics, Finance and International Trade; Astana
}

Diana Ismailova

PhD, Profesoor; Academy of Imageology; Astana

\author{
Doi:10.5901/jesr.2015.v5n3p145
}

\section{Abstract}

The purpose of this article is to reveal attractive invariants in female management style. The authors explored the trends and strategies of female management based on two primary methods: a) the method of lenient interview, used for specifics of female management detection and evaluation of a woman-in-chief themselves; b) questionnaires of team management and the staff office of the companies about the layer of gratification with the management and features of female mind. The relevance of the problems researched by the authors in the work lies in the aspects of psychological, social, philosophical, pedagogical sciences and imageology. Each of these sciences refers to the process of derivation, development and functioning the influence of image of a female-manager. The representatives of these scientific try to explain a human behavior, a person formation and his structures, research the mechanisms of human perception by a human being. The problem of derivation, evaluation and essence of image in kazakhstanian psychology has appeared only in the last decades. First of all it caused by the changes in the political and social situations in the society. As a result the research object has to be the image itself, and the image of state and political personalities, businessmen, art and culture employees.

Keywords: female management, gender politics, attraction, carrier, imageology, image technologies

\section{Introduction}

Interview and questionnaire survey was taken into account during the task of female management study without triggering additional contradistinction associations, so many neutral attitudes were suggested. Regarding to this, the respondents were told that the matter investigated was the technology of company management in Kazakhstan in current times.

During the interview, the dialogue was hinged on four primary aspects: distinctions of management in modern times; optimal strategies and managerial style, assisting success in companies; evaluation of a personnel managerial style and its success for company's activity; evaluation of the management efficiency level on the theatrical role of staff and the management team.

The questionnaire survey included the evaluation of managerial style satisfaction level on the part of staff and team, the image of the effective manager against the real managerial qualities, the currency of certain technologies in the activity of female top-manager.

The study, which was taken in 2011-2012 included the interview with 35 female managers of Astana city private companies, primarily in the service sector (real estate companies, tourism, consulting, large commercial establishments, including wholesale and others). The manpower in those companies was about 15 to 87 persons. The questionnaire survey among members of managerial staff and the team was conducted in 10 companies. The total of 148 persons were questioned, among them: 84 female and 64 male. In every organization, approximately 10 or 18 persons participated in the questionnaire.

\section{Research Methods}

In their scientific paper the authors used the following research methods: the analyses of scientific literature, psycholinguistical methods, method of expert evaluation: cases, essays, interview, statistical methods, also:

1. A set of diagnostics instruments, including: a standardized method of multivariate study of personality LN Sobchik (SMIL); method of diagnosis of interpersonal relationships, a modified version of interpersonal 
diagnostic T. Leary (DHS); Tests Amthauera, Guildford, Rosenzweig, Solomin, Naps1 projective test.

2. Methods "Assessment imidzheobrazuyuschih professional and personal qualities of leadership" (UV Andreeva, 2002);

3. Methods "Assessment imidzheobrazuyuschih stylistic qualities of leadership" (UV Andreeva, 2002);

4. The method of "Expert evaluation image of the head of women" (TN Matveeva, 2005);

5. Method "Assessment of attraction image of the" ideal "and" real "head" (VN Futin, TI Klochkova, 2009).

\section{Female Management in Kazakhstan Companies: An Attractive Image of Female Managers}

The change in economic development in Kazakhstan, rampant growth of private property institution, and alteration in policy encouraged the establishment of a new social class of people. They made gains thanks in no small part to their force and professional accomplishments, they are entrepreneurs, managers, and political leaders actively involved in economic and political processes of the nation. The interest in the problem of career advancement was increased by the appearance of new elite business representatives in the society. The successful realization of individual social managers draws public attention to its implementation mechanisms, thus there appears to be a social order for survey work in the field of management, psychology and development of successful self-presentation models as a part of image psychology. In the business arena, during the transition of management organization from a shape of "a wild market" to "a liberal stability," the reason of the moral and ethical values, such as "impeccable reputation" and "positive public view," has become of great importance once again. At the moment, the society created a unique opportunity for studying a personal fulfillment, the formation of new image technologies, which allows acreation of a positive image of the subject, specifically of femalemanagers. This is as much as to make a norm accepted by our society and demographic changes. The situation of women in the professional sphere continues to be stunted with encroachment on women's rights in the labor market not allowing them an equal opportunity for progression in their career like men. For this reason, the problem of women's career advancementis eluded by a positive image in particular, which is a factor conducive to professional development at the very development stage of modern society. In the views of some western authors [Ageev, V.S.,1990] there are "traditionally female business sectors": food services, public services, retail business, hotel industry, etc. The kazakhstanian researchers also tend to argue that the industry specific of the "female business" in the context of Kazakhstan can be traced quite clearly. In the industry, agriculture, wholesale trade, activity on market functioning maintenance, and financial sector, the proportion of female entrepreneurs ranged from 13\% (in the industry) to 20\% (in finance). Women more actively explore the retail, catering, science, culture, and health care spheres where the proportion of entrepreneurs is ranging from $39 \%$ (in retail) to $56 \%$ (in science). These findings are consistent with data from other surveys, which confirms their validity [Abulkhanova-Slavskaya K.A., 2002, 179 p.].

Reasons of economic character are named not only among the factors of the given industrial specification. Most authors, investigating the given problem, have a great mind to place a priority on reasons of social- psychological nature. That is to state that these reasons define "a key for upping permeability" of concern for women in those fields. The first and foremost involves patience, the ability to make arrangements with partners, governance, and "domestication" of business. However, one must admit, for economic figures a number of enterprises governed by women are inferior to those governed by men. This tendency which was revealed for the first time in the western companies, remains valuable in Kazakhstan. In the estimation of researchers, this can be affected by various factors. The most critical ones are as follows:

1. female entrepreneurship is concentrated in spheres, the technology of which does not assume a large number of workers;

2. female entrepreneurs are mostly oriented on their own time control, even detriment of profit improvementand an attempt to find a balance between home and work act as a limitation of expanding enterprise size (this is not limited only to Kazakhstan).

In many regards a decent size female-run commercial enterprise is defined by "considerable years" vested in women entrepreneurs. The most intensive invasion of women into the entrepreneurship can be picked up during the last two years, which is related to considerable reduction in the "game rules," indefiniteness, and volatility of outcomes in the business environment. Therefore, according to questionnaire survey, the percentage of women who had entered into business in the early 2000 -th comprising $33 \%$, while in 2011 it contracted by half (17\%).

However, socioeconomic explanations of this phenomenon should be supplemented. In our point of view, an analysis of female management features, its technology allows considerable expansion of potential explanatory hypotheses due to socio-psychological, not just socioeconomic factors. 
Let us consider the image notion itself. In the mid-1980-th, the image became an object of social involvement and scientific-psychological study. A keen interest to the problem of image was a result of the change in socioeconomic living conditions of the society at the end of the $20^{\text {th }}$ century and the development of market economy in the country. This involvement resulted in the competition and selling race, leading to an explosive development of PR-technology, practical image-making, design, and other applied sciences involved with sales and services promotion in a competitive environment. A practical inquiry for playing out the issue of image has resulted in the establishment of a new science "imageology," which started at the junction of sciences such as philosophy, psychology, sociology, politology, culturology, economy, customology, history, and others [BrizhanE.S., 2005, p. 251-254 ]

The subject of imageology is "the study of the role and functions of image in social being, theirphyletic and ontogenetic backgrounds, conditions, driving forces and laws of formation, functioning, managing, as well as the description and development of cause-and-effect relationsbetween various images (people, organizations, social and political movements, goods, services, etc." [Petrova E.A., 2003, 166 p.].

Most reference works interpreted the notion of image as: "an intentional image-building" [ProhorovA.M., 1981. 1600 p.]; "an appellative image formed in the mass consciousness and applied as a stereotype" [FridmanЛ.M, 1991. p. 288] "a set of conspicuous qualities, which people associate with the individuality" or as "a visualization of something abstract and concrete seen before, and strongly resembling the other in realization."

The image of an accomplished manager in the modern social psychology is considered as a part of management psychology and analyzed in keeping with the following issues: the formation of organization image, influence of image on business relations, interrelation between professional and personal image qualities of the manager, perception of the management team, perception of the manager, notion of an ideal manager, communicative qualities of the manager, psychological personality characteristics of the manager, psychological aspects of professional activity of the manager, gender aspects in the management, gender behavior patterns connected with the modern personality of the manager, issues of inter-individual understanding among the group, semantics of inter-individual relations, gender and ethnic aspects, dominance psychology, etc. The manager image is an "integrated, individual characteristic of his managerial (professional) and personal qualities, which in a form of integral image, is represented on team members and other persons, who are of a direct or indirect interaction" [Abulkhanova-Slavskaya K.A., 2002. 179 p.].

\section{The Problem of Attractive Image Derivation of a Woman-Manager Image}

The modern surveys of V.A. Labunskaya, L.V. Lapteva, E.A. Petrova, E.V. Perelygina and others in the sphere of imageology suggest that the consideration for influence of stereotypes developed in the society is not allowedwhen image building is prevalent.

Recently, in the society, there has been a fairly common opinion about the superiority of men over women. This setting was formed a long time ago. For instance, in the book of O.Weininger "Sex and character," the first Russian translation of which was printed in 1912. When speaking about the differences in adult male and female psychology, he noticed the absence of judgment, character, and will of the latter. This leads to the fact that a woman would never understand a man, carrying all of these.

In a traditional way, V.A.Labynskayawrote in her book "Social psychology of personality: questions and answers" published in 2001 about "a rooted" stability of stereotypes of women's place in the society and gives a historical opinion survey of foreign researchers on the given problem. Agreeing to her, toward the close of the 1950s, Maccy, Sheriff, O'Leary in the forms of traditional European culture specified the following outstanding characteristic features of men's image: competency, rationality, activity and efficiency, and socially unlimited mode of behavior [Labunskaya V. A., 2013.].

A typical woman's image, on the contrary, refers to the following characteristics: emotional support, warmness of feelings, a high degree of empathy, and dedication to socially communicative abilities. While men generally have more advantages over women, and the success of men in professional sphere is most often justified by their ability, women's success is viewed as a result of good fortune and other "unstable reasons" [Kiesler S.B.,1975. v. 5. p. 98-110].

Psychologists mentioned the fact that in a conservative society the competence in a personal approach for women turns out to be a disadvantage. Highly competent women-specialists are not desirable amongboth women and men. This is because they tend to encroach upon the hierarchy between men and women and negate current stereotypes. The given fact finds its affirmation in R. Hagen, A. Kan research works (1975). They found out that under the conditions of cooperative as well as competitive interrelation, both men and women strive to eliminate competent women from their group. [Hagen R.L., Kahn Л. , 1975. V. 5. № 4. P. 362-376].

The research works in this sphere show that a serious career advancement and attainment of authority in the 
business community is not possible without causing a positive business image. Image of businesswoman is an intricate creation of an inimitable, confined, integral, and nimble image, and a constant devotion of attention to it. The image has to be formed in two basic ways: 1) conformity to the requirements of the mass-communication channel (TV, mass media, etc.), i.e. audio and visual information: mode of dress, manner of speaking, certain hairstyle, outlook, pose, gestures, body languages, etc. In other words, $69 \%$ of this data about people cannot be reproduced in words. 2) characteristics or features, which are considered important in a business environment, e.g. way of thinking, intellect, interests, valuable qualities, hobby, creative ideas, etc. These exhibit professionalism, confidence, and authority. On one hand, personal characteristics are positively valued by the wider public. On the other hand, a successful business image results in not only an individual perception by also in the business environment. E. Simpsondefines the personal image as a combination of external and internal factors, specifying a self-image, which reflects the state of self-esteem, detected image, that is to say the opinion of people about personality and requested image, which supposes the conformity to a definite image characteristic. Personal image has an effect on one's own personality quite as much as on the surrounding people.

There is a wide range of principles of business image formation. The principal ones are: 1) realistic, unbiased selfassessment; 2) taking into account expectation of business environment; 3) a clear, explicit stated goals; 4) the change of own image towards the better professionalism; 5) the creation of business image in different directions; 6 ) the conformity to the basic parameters of the selected picture.

Amid the crisis, conflict situations require not only a flexible constructive technology. The key element of the professional competence of female managers is the ability to negotiate without bringing defeat to herself and her opposition. "Our collaborators at the bargaining table, as mentioned by one of lady-manager, are armed with emotions, profound adherence to definite valuable qualities, and different point of views. Moreover, they are unpredictable. This fact could be useful or destructive during negotiations. Everything depends on your ability to compel him to work hard while hitting the target."

\section{Conclusion}

Then and there, the dedicated research study suggests that women managers do not tend in the business activities to an enhanced demonstrativeness and excessive generosity; on the contrary, they prefer a more moderate assessment of such characters. At the same time they exhibit high ethical standards opting to "honest" relationship instead of "false" one. According to the results, such personal qualities in the pattern of self-esteem, as modesty, honesty and friendliness, received $50 \%$ and more with the highest possible score (5 points). The following business qualities: diligence, responsibility, and equability of mind have also exhibited the maximum score. The lowestscores were given to the following qualities: activity, generosity, blind confidence, and sociability. Thus, the opinion existing among people that a womanis a soft and trusting manager, is not confirmedby the evaluation, given by female manager themselves with their quality and style of management.

Even though an ideal image among women shifted toward a humane manager the personal management style that they are driven to realize in a particular company, in like vein can be traced to a certain level.

In fact, questionnaires are basically rating scales consisting of 18 pairs of personal qualities. The left side contains a set of negative personal qualities; the right contains positive ones. The objective of respondents was to measure the degree of expressiveness of these calibers in the image of a successful manager, in his own personality or both a successful leader and director, in case that he was valued by the members of the management team or staff. The respondents rated scores (from1 to 5).

\section{References}

Ageev, V.S. (1990). Intergroup interaction: Socially-psychological problems. Moscow: MGU.

Abulkhanova-Slavskaya K.A. (2002). The relationship of professional and personal qualities of the head image: PhD dissertation. ... Cand. Sc.(Psychology): Kazan, 2002. 179 p.

Brizhan E.S. The image of a business woman as a factor in career advancement //"Imageology - 2005": phenomenology, theory, practice: Proceedings of the $2^{\text {nd }}$ International symposium for imageology. I Under edition of. E.A. Petrova. Moscow:RITSAIM. Moscow, 2005. p. 251-254.

Petrova E.A. Psychosemiotics subject environment as the factor of formation of personal image: PhD dissertation. ... Cand. Sc.(Psychology): Moscow. 2003. 166 p.

ProhorovA.M. Soviet Encyclopedia. Moscow: 1981. 1600 p. 
Fridman Л.M., A psychological guide teachers. Moscow: Prosvyascheniya, 1991. 288 p.

Labunskaya V. A. Psychology of communication difficulty. Moscow: 2013.

Kiesler S.B. Actuarial prejudice towards women and its implication // J. of Appl. Soc. Psychol. 1975. v. 5. p. 98-110.

Hagen R.L., Kahn Л. Discrimination against competent women // J. of appi. social psychology. 1975. V. 5. № 4. P. $362-376$.

Miller V.K. English-Russian dictionary. Moscow: OGIZ, 1948. 
